\title{
Thermal Conductivity of Natural Fiber, Glass Fiber \& CNTs Reinforced Epoxy Composites
}

\author{
K. Srinivasulu Reddy ${ }^{*}$ and D. Sreedhar ${ }^{2}$ \\ ${ }^{1}$ School of Mechanical, Chemical \& Materials Engineering, Mechanical Design \& Manufacturing Engineering Program, Adama Science \& \\ Technology University, Adama, Ethiopia \\ 2Dept. of Mechanical Engineering, Sreenidhi Institute of Science \& Technology, Hyderabad, India
}

Accepted 12 July 2016, Available online 15 July 2016, Vol.6, No.4 (Aug 2016)

\begin{abstract}
Epoxy composites consisting of sisal, glass fibers and Multi walled carbon nanotubes(MWCNTs) were fabricated by three different methods like Hand layup, unstretched fibers and stretched fibers methods. Test specimens prepared as per ASTM standards using Vinyl ester thermosetting resin as matrix and reinforced with different weight percentages of sisal, fiber glass and 1\% of MWCNTs. Specimens were prepared using stretched fibers by hand lay-up process in open moulds. Thermal contact conductance (TCC) is used to analyze heat transfer across the two solid contacting surfaces at different temperatures. It is found that TCC of 4\% sisal-4\% glass fiber and 1\% MWCNTs sample has highest thermal conductivity of $16 \mathrm{~W} / \mathrm{mK}$ at $100^{\circ} \mathrm{C}$. It is observed that the presence of nano interstitial material in FRP composite has improved the thermal conductivity in the subjected temperature range.
\end{abstract}

Keywords: Thermal contact conductance, sisal fiber, MWCNTs, vinyl ester thermosetting resin

\section{Introduction}

Many composite materials are composed of two phases one is termed as matrix phase, which is continuous and surrounds the other phase often called the reinforcement phase or dispersed phase. The reinforcement is stiffer and stronger than the matrix, and gives good properties the composite. The matrix holds the reinforcements in orderly pattern. The matrix materials can be metallic, ceramic or polymeric. Metal matrix composites (MMC) consist of a matrix of metals or alloys reinforced with metal fibers such as carbon and boron. When the matrix is a polymer the composite is called polymer matrix composite (PMC). Ceramic matrix composites (CMC) consist of a matrix reinforced with ceramic fibers such as silicon carbide and alumina. The reinforcing phase can either be fibrous or nonfibrous (particulates) in nature. The fiber reinforced polymers (FRPs) consist of fibers of high strength and or bonded to a matrix with a distinct interface between the fiber and the polymer. In this form, both fibers and matrix retain their physical and chemical properties as stated by John et al (2007) and Khalil et al (2007).

Externally applied stress is transmitted and distributed to the fibers as the matrix phase binds the

*Corresponding author K. Srinivasulu Reddy's Phone: +251 962103204

DOI: dx.doi.org/10.14741/Ijcet/22774106/6.4.2016.18 fibers together, hence major portion of the load is taken by the fibers and very small portion of the applied load is taken by the matrix phase. Fibers are basically two types, natural and synthetic. Jute, cotton and sisal are some examples for natural fibers and nylon, glass, and carbon are some examples for synthetic fibers. Recently, natural fibers as reinforcement attracted the attention of engineers because of their advantages over other established materials. They are fully biodegradable, abundantly available, environmentally friendly and renewable. Plant fibers are light compared to glass, carbon and aramid fibers. Biodegradability of plant fibers can contribute to a healthy ecosystem while their low cost and high performance fulfills the economic interest of industry. It has been found that natural fiber composites possess good thermal and acoustic insulating properties, higher resistance to fracture and better electrical resistance properties. Also, natural fibers show superior mechanical properties such as stiffness, and modulus compared to glass fibers. On the other hand, there are also some disadvantages, like variations in quality, moisture absorption and low thermal stability.

Many investigations proved that natural fibers are potential reinforcements for composites and results have shown that the natural fiber composites own good stiffness but the composites do not reach the same level of strength as the glass fiber composites as stated by Oksman et al (2003). Hybrid composite 
materials are made by combining two or more different types of fibers in a common matrix. Hybridization of two types of short fibers having different lengths and diameters offer some advantages over the use of either of the fibers alone in a single polymer matrix. Most of the studies are on the hybridization of natural fibers with glass fibers to improve the properties as stated by Jarukumjorn et al (2009). They possess good calorific value and cause little concern in terms of health and safety during handling. In addition, these exhibit excellent mechanical properties, with low density and are inexpensive. This good environmental friendly feature makes the materials very popular in construction and automotive industry. Hence in this investigation, hybrid composite material is selected.

Madhusudana et al (2014) investigated mechanical properties of hybrid composite material made up of sisal fiber and rice husk reinforced with epoxy. Srinivasulureddy et al (2015a) investigated tensile, flexural and hardness properties of sisal fiber, fiber glass and MWCNTs reinforced with epoxy in three different methods viz. unstretched, stretched and layer by layer methods. It is found that UTS is higher in stretched method with sisal, sisal + glass fiber and sisal + glass fiber and MWCNTs. It is observed that there is an improvement in UTS when fabricated in stretched fabric method at $10 \%$ by weight of Sisal, Sisal \& glass fiber. There is marginal improvement in strength and hardness when 1\% MWCNTs are added. There is reduction in shore $\mathrm{D}$ hardness of the specimen when reinforced with sisal and Glass fiber as claimed by srinivasulureddy et al (2015b). There is small improvement in Hardness when 1\% MWCNTs are added. With this background, in this present investigation an attempt has been made to fabricate the samples using stretched fabric method and evaluate the thermal conductivity properties of sisal fiber reinforced hybrid composites.

\section{Materials and Methods}

Basic specifications of various materials used in this study are given in below table.1. Research grade MWCNTs was supplied by M/s Sigma Aldrich, USA. Properties of MWCNTs are shown in table 2.

Table 1: Materials and its properties

\begin{tabular}{|c|c|c|}
\hline S. No & Materials & Specifications \\
\hline 1 & $\begin{array}{c}\text { Unsaturated } \\
\text { polyester resin }\end{array}$ & $\begin{array}{c}\text { Density: } 1.13 \mathrm{~g} / \mathrm{cm} 3, \mathrm{UTS}: 70 \mathrm{MPa}, \\
\text { Flexural Strength:115MPa Heat } \\
\text { distortion temperature:102 0 C }\end{array}$ \\
\hline 2 & Sisal fiber & $\begin{array}{c}\text { Density: } 1.450 \mathrm{~g} / \mathrm{cm} 3, \text { diameter: } \\
50-300 \mu \mathrm{m}, \mathrm{UTS}: 5.40 \mathrm{MPa}, \\
\text { Cellulose: } 65 \%\end{array}$ \\
\hline 3 & Glass fiber & $\begin{array}{c}\text { Density: } 2.55-2.60 \mathrm{Mg} / \mathrm{m} 3, \mathrm{UTS}: \\
1950-2050 \mathrm{MPa}, \mathrm{Thermal} \\
\text { Conductivity: } 1.2-1.35 \mathrm{~W} / \mathrm{m} . \mathrm{K}\end{array}$ \\
\hline 4 & $\begin{array}{c}\text { Cobalt } \\
\text { (Accelerator) }\end{array}$ & Density: $0.98 \mathrm{~g} / \mathrm{cm} 3$ \\
\hline 5 & $\begin{array}{c}\text { Methyl Ethyl } \\
\text { Ketone peroxide } \\
\text { (MEKP) Catalyst }\end{array}$ & Density: $1.17 \mathrm{~g} / \mathrm{cm} 3$ \\
\hline
\end{tabular}

Table 2: Properties of MWCNT

\begin{tabular}{|c|c|}
\hline Properties & Values \\
\hline Purity & Carbon $>90 \%$ (trace metal basis) \\
\hline OD*ID*L & $10-15 \mathrm{~nm} * 2-6 \mathrm{~nm} * 0.1-10 \mu \mathrm{m}$ \\
\hline Impurities & $\begin{array}{c}\text { Amorphous carbon, none detected by } \\
\text { transmission electron } \\
\text { microscope }(\mathrm{TEM})\end{array}$ \\
\hline Melting Point & $3652-3697^{\circ} \mathrm{C}$ \\
\hline Density & $\sim 2.1 \mathrm{~g} / \mathrm{ml}$ at $25^{\circ} \mathrm{C}$ \\
\hline
\end{tabular}

Specimens were prepared as per ASTM D3039-76 standards and die dimensions are $250 \times 25 \times 10 \mathrm{~mm}$ as shown in fig.1. After the calculation of volume fraction, Unsaturated Polyster Resin (UPR) is mixed with Promoter, Accelerator and Catalyst at $1.5 \%$ by volume to UPR and stirred with magnetic stirrer for 5-10 minutes continuously. Samples were prepared in the weight ratio of $2,4,6,8$, and $10 \%$ of sisal and glass fiber to the UPR. Multi walled carbon nanotubes (MWCNTs) are the reinforcement at $1 \%$ by weight as the literature revealed that beyond 1\% addition of MWCNTs leads to agglomeration issues. The fabrication process is adopted is hand lay-up in open mould as shown in fig.2. Resin is filled in the die first and the prepared set of natural fibers placed in the resin hardener without any gap. Rollers are rolled during the preparation of the sample in the die. Again the die is filled with resin layer by layer. This process is simultaneously done till the height of the die $10 \mathrm{~mm}$. The setup is kept in a dry place for 24 hours. After 24 hours the specimen is taken away from the die and finally the natural fiber composite is fabricated. Test specimens were prepared using stretched fabric method and different samples prepared with sisal, sisal-glass fiber and sisal-glass fiber-MWCNTS are shown in fig. $3,4 \& 5$.

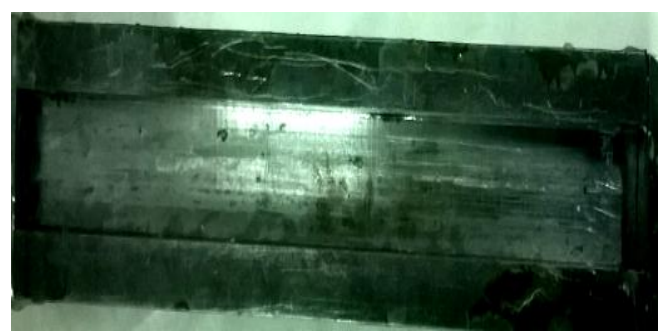

Fig.1 ASTM standard die

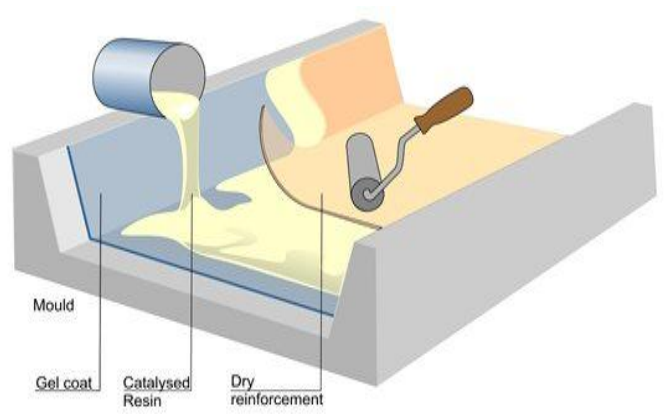

Fig.2 Open mould hand lay-up process 


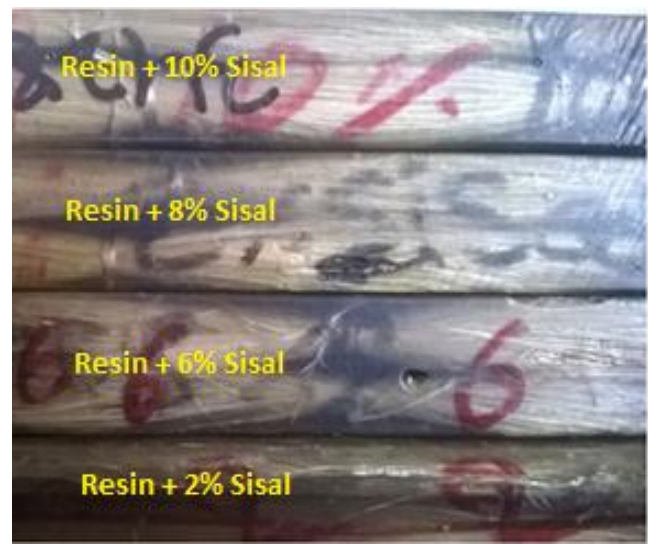

Fig.3 Sisal reinforced UPR

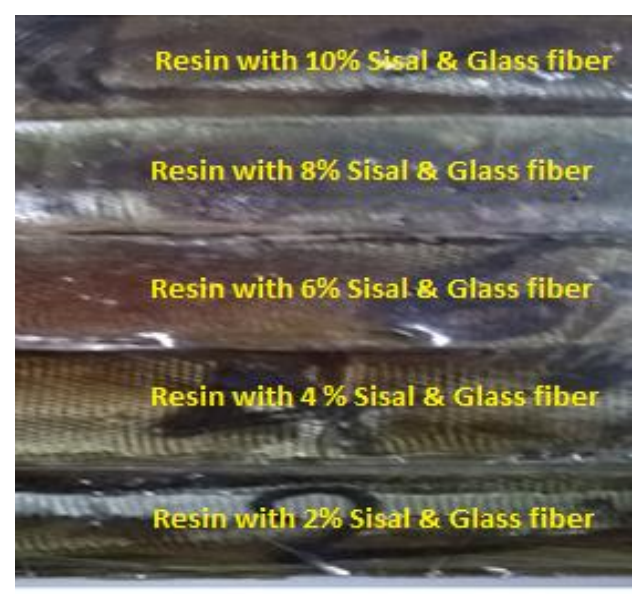

Fig.4 Equal percentages of Sisal \& Glass fiber with UPR

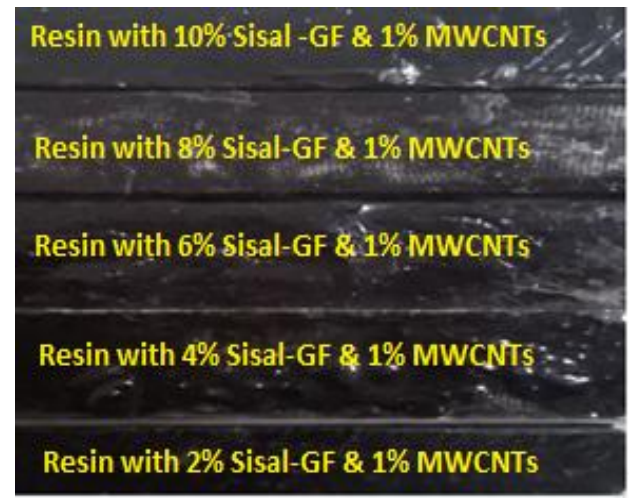

Fig.5 Equal percentages of Sisal, Glass fiber and 1\% of MWCNTs with UPR

\section{Experimentation}

Thermal contact conductance (TCC) is used to analyze heat transfer across the contacting surfaces two solids at different temperatures. It finds many engineering applications in the field of automotive, electronics and metal processing industries. Experimental investigation of TCC across contacts of cylindrical copper specimens in the presence of nano-interstitial material is found with the test facility consisting of both heating and cooling provisions on either side of the contact under the investigation as shown in the Fig. 6 and temperatures are measured using the thermocouple wires which are connected across the copper specimens whose thermal conductivity is known $(381 \mathrm{~W} / \mathrm{mK})$ as shown in Fig.6. Thermal conductivity of the sample is calculated using the standard equation (1) having sample diameter of $2.5 \mathrm{cms}$ and length of $0.6 \mathrm{cms}$.

$K=\frac{Q^{*} L}{A^{*} \Delta T}$

Experiments were conducted to find the TCC by varying the percentage of sisal, sisal - glass fiber and sisal-glass fiber \& 1\% MWCNTs. Temperature variation with distance from the sample are recorded using thermocouples using Keithley data acquisition system as shown in fig. 7 to fig. 13 .

\section{Results \& Discussion}

Thermal conductivity values calculated using equation (1) are presented in fig.14. It is found that TCC of $4 \%$ sisal-4\% glass fiber and 1\% MWCNTs sample has highest thermal conductivity of $16 \mathrm{~W} / \mathrm{mK}$ at $100 \mathrm{oC}$. It is observed that the presence of nano interstitial material in FRP composite has improved the thermal conductivity in the subjected temperature range. It is observed that TCC of $4 \%$ sisal $+4 \% \mathrm{GF}+1 \% \mathrm{MWCNT}$ is higher compared to $5 \%$ sisal $+5 \% \mathrm{GF}+1 \% \mathrm{MWCNT}$ at $100^{\circ} \mathrm{C}$. SEM image of $4 \%$ sisal, $4 \%$ glass fiber and $1 \%$ MWCNTs specimen is shown in fig. 15 and the presence of MWCNTs without clustering is observed.

\section{References}

Abdul Khalil H. P. S. et al (2007), The effects on mechanical and physical properties of oil palm fiber (efb)/glass hybrid reinforced polyester composites, Journal of Reinforced Plastic Composites. 26(2), 203-218.

Jarukumjorn K et al (2009), Effect of glass fiber hybridization on properties of sisal fiber-polypropylene composites. Composites Part B; 40(7):623-7

John $\mathrm{K}$ et al Chemical resistance studies of sisal/glass., fiber hybrid composites, Journal of Reinforced. Plastic Composites. 26(4) (2007) 373-376.

Madhusudhana et al (Aug 2014) Experimental investigation of mechanical properties of sisal fiber and rice husk reinforced polymer composite, Journal of Mechanical and Civil Engineering, Vol. 11, Issue 4,

Oksman K, Skrivars M, Selin JF. (2003), Natural fibers as reinforcement in polylactic acid (PLA) composites. Composites Science and Technology; 63(9):1317-24.

Srinivasulu K, et al (August 2014)Fabrication and Study of Mechanical Properties of Sisal, Glass Fiber and MWCNTS Reinforced Polymer International Journal of Innovative Research in Science, Engineering and Technology, Vo.4, Issues 8,

Srinivasulu K et al (2015), Fabrication and Mechanical Properties of AlSi12 NanoParticulate Composite Procedia Materials Science 10, 149-158. 